\title{
Primary thrombosis of pulmonary artery in a child with tetralogy of Fallot
}

\author{
SIVERT SVANE ${ }^{1}$ \\ From the Institute of Pathology and the Department of Surgery A, Rikshospitalet, \\ University of Oslo, Oslo, Norway
}

\begin{abstract}
A 34-month-old child with tetralogy of Fallot developed an acute, primary thrombosis of the pulmonary trunk. A greatly increased haematocrit was most probably a predisposing factor. An unusual postmortem finding was the large number of extremely dilated myocardial capillaries. In a review of a series of 394 consecutive necropsy cases with many kinds of cardiac anomalies, there was only one case (a 28-year-old man) with occluding thrombus formation in the pulmonary artery. This case also belonged to the Fallot group but a subacute glomerulonephritis seemed to be the major cause of death.
\end{abstract}

Thrombosis of the pulmonary trunk or its two main branches is regarded as a rarity in children (Gootman et al., 1964). The majority of the paediatric cases have been thought to be primary thromboses in contrast to the secondary thrombi superimposed upon a previous pulmonary embolus. Pulmonary arterial thrombosis in childhood has mainly been reported in connection with dehydration (Rauchfuss, 1859; Gunter, 1941; Ball et al., 1956; Brunk, 1959), broncho-pulmonary infections (Robin, 1875; Gehrt, 1923), nephrosis treated with corticosteroids, chlorothiazide, or spironolactone (Gootman et al., 1964; Symchych and Perrin, 1965; Rosenkranz and Weissenbacher, 1967; Levin, 1967; Habib, 1968) and congenital heart disease. We describe here an example of the last-mentioned type which had unusual features.

\section{Case report}

This 34-month-old boy was of a healthy family. During his first year of life he had frequent episodes of intense cyanosis and dyspnoea, particularly after crying. Later, there was a certain improvement with less obvious cyanosis. During a hospital stay a year before death, a diagnosis of tetralogy of Fallot was made; the haematocrit then was 59 per cent. It was decided to postpone surgery for one or two years.

During the following year, however, his cyanosis and dyspnoea became progressively worse. One 1 Present address: Department of Surgery, Central Hospital for
Ostfold, 1600 Fredrikstad, Norway. day he suddenly collapsed and developed rapidly increasing dyspnoea and cyanosis. A few hours later, he lost consciousness. There were no convulsions or pareses. On admission to hospital shortly afterwards, he was deeply cyanotic, cold, and unconscious. Respiration was deep and the rate was slightly increased. There was only time for a

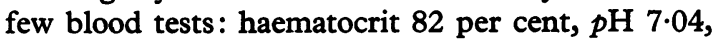
standard bicarbonate $10 \mathrm{mmol} / \mathrm{l}$, and $\mathrm{PCO}_{2} 39$ $\mathrm{mmHg}$. He was treated with oxygen, careful venesection, and digitalis without effect, and died 10 hours after the onset of the attack.

\section{Necropsy}

Length $85 \mathrm{~cm}$, weight $14 \mathrm{~kg}$. There was pronounced diffuse cyanosis, with some foamy, blood-tinged fluid in the nostrils.

The lungs were dark and congested without signs of infarction or pneumonia. Microscopically, the dominant feature was a generalised occlusion, particularly of the minor vessels, caused by massive aggregates of conglutinated erythrocytes (Fig. 1), some of them more or less hyalinised. There were scattered small deposits of intravascular fibrin, and many of the red cell aggregates were partly coated by fibrin positive material (the Martius-scarlet-blue stain). Fibrin was not seen in the vessel walls.

The heart was enlarged (weight $105 \mathrm{~g}$ ). The right ventricle was dilated and greatly hypertrophied. There was a diffuse subepicardial extravasation of blood. The aortic arch was moderately dilated and located on the left side. The ductus arteriosus was 
unidentifiable. The cardiac anomaly was a typical tetralogy of Fallot with slightly hypoplastic pulmonary arteries and pronounced infundibular stenosis of the right ventricle. The entire stem of the pulmonary artery was completely occluded by an adherent, apparently fresh thrombus which extended $3 \mathrm{~mm}$ into both main arteries (Fig. 2). The microscopical picture of the right ventricular myocardium was dominated by a remarkably large number of enormously dilated capillaries crammed with erythrocytes, but without the typical red cell aggregates as seen in the lungs (Fig. 3). Similar, but less pronounced, capillary changes were seen in the left ventricular myocardium. Microscopy also showed numerous minute myocardial haemorrhages and scattered degenerative changes (fragmentation, hyalinisation, loss of striation). Sections from the

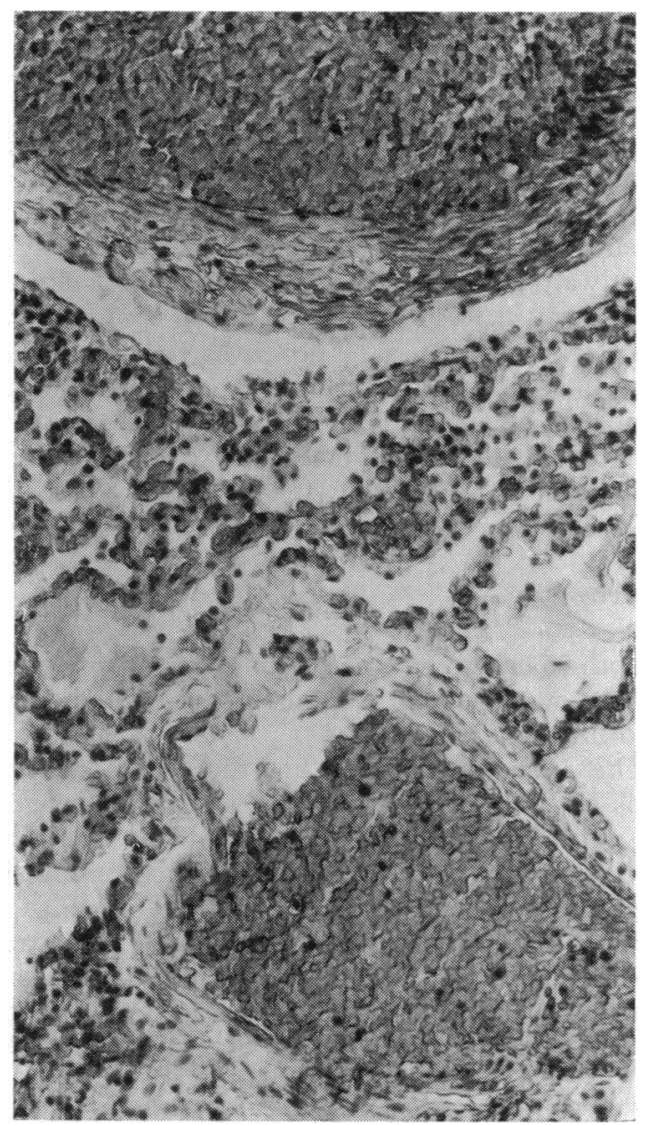

Fig. 1 Section from lung showing the generalised occlusion of capillaries and minor vessels resulting from formation of massive aggregates of conglutinated erythrocytes. pulmonary artery showed fresh thrombus masses and some small, organised parietal thrombi.

The liver was enlarged (weight $400 \mathrm{~g}$ ) as a result of subacute congestive changes. The kidneys were also congested. Some small cortical vessels were occluded by conglutinated red cells, and a few of them contained minute amounts of fibrin. Similar changes were also seen in the spleen, pancreas, adrenals, thyroid gland, anterior lobe of the pituitary, and in numerous lymph nodes from various regions.

The cerebrospinal fluid was blood-tinged. Macroscopically, the brain was soft, oedematous and cyanotic with a remarkable congestion of the choroidal vessels. In the left lateral ventricle small clots were seen, probably caused by minor bleeding from the choroid plexus. Microscopy of the brain was not performed.

The large abdominal, thoracic, and pelvic veins showed no signs of thrombosis.

\section{Discussion}

Widespread and progressive thrombosis of the pulmonary vessels of microscopical size occurs frequently in patients with congenital pulmonary

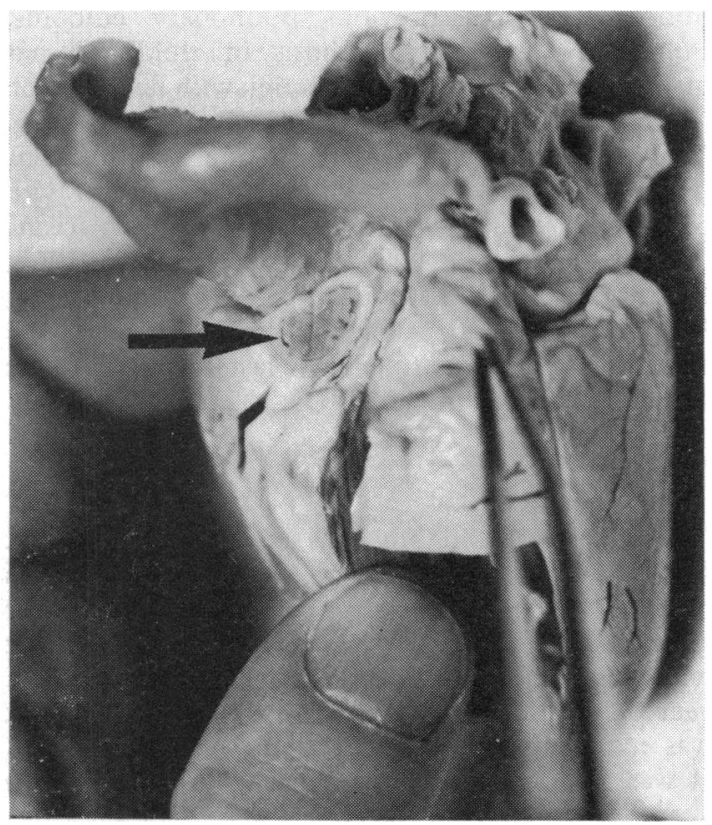

Fig. 2 The base of the heart (formalin-fixed specimen). The pulmonary trunk is cut through. The arterial lumen is completely occluded by a fresh, adherent thrombus (arrow). 
artery stenosis (tetralogy of Fallot type). These thrombi occur independently of any operative procedure (Rich, 1948; Tosetti et al., 1953; Best and Heath, 1958; Ferencz, 1960, 1964; Thomas, 1964). It has been suggested that the predisposing factors are the increased viscosity of the blood resulting from compensatory polycythaemia, and the reduced flow in the pulmonary vessels (Rich, 1948; Best and Heath, 1958). A remarkable tendency to recanalisation of the thrombi of the lungs, producing a characteristic appearance of the arteries with multiple lumina, has also been noted (Rich, 1948; Tosetti et al., 1953). Severe microscopical pulmonary thromboses have been seen in patients who die during a cyanotic spell (Ferencz, 1960, 1964).

Massive macroscopical thrombosis involving both pulmonary arteries was seen in a 14-month-old infant with tetralogy of Fallot (Ring and Bakke, 1955). Similar changes were found in a $4 \frac{1}{2}$-year-old child with pulmonary stenosis and ventricular septal defect (Dickinson, 1897), in an 8-month-old infant with pulmonary atresia and terminal diarrhoea (Ball et al., 1956), and in a 13-year-old patient with stenosis and subacute bacterial endarteritis of the pulmonary artery (Gordon and Perla, 1931). A ventricular septal defect was present in a 7-year-old patient, but in this case the possibility that trauma to the chest had played some part in the production of the defect must be considered (Harvey and Hogg, 1946).

Pulmonary arterial thrombosis has also been seen in a number of adult cases with cardiac anomalies, such as ventricular or atrial septal defects and persistent ductus arteriosus (Amos, 1958; Hudson, 1965).

In some cases, a more chronic thrombotic process of the pulmonary artery has been misinterpreted clinically as congenital heart disease, in children (Whipham, 1911) as well as in adults (Dimond and Jones, 1954; Breining, 1965).

In our case, an acute crisis apparently developed after a period of increasing severity of symptoms. It seems reasonable to relate the terminal events to the distinctly raised haematocrit value, which entails a considerable rise in blood viscosity

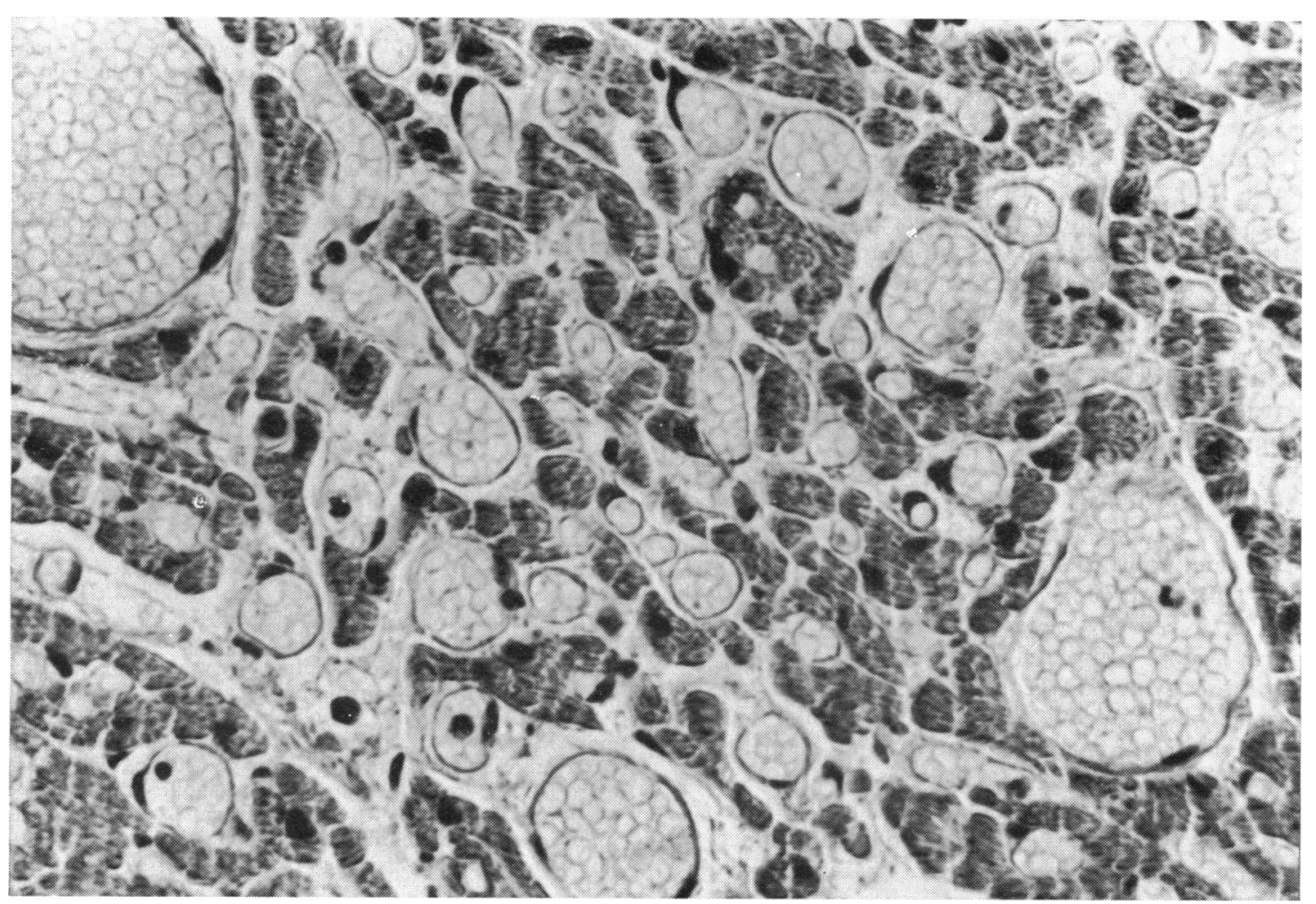

Fig. 3 High power view of the right ventricular myocardium showing the large number of enormously dilated capillaries between the muscular elements. 
(Rudolph et al., 1953). Harvey and Hogg (1946) have emphasised that one must suspect the possibility of pulmonary arterial thrombosis when a patient, who has congenital heart disease, develops a conspicuous increase in the severity of his symptoms. The onset may be acute with vomiting, perspiration, cyanosis, and collapse. Praecordial pain is usually a presenting symptom, but pain may be anywhere in the chest.

The postmortem demonstration of massive, widespread aggregates and intravascular fibrin deposits in our case aroused the suspicion of a terminal disseminated intravascular coagulation. Though we do not consider our findings as conclusive, we find it noteworthy that recent studies have suggested that a consumption coagulopathy may occur in certain cyanotic patients (Ihenacho et al., 1973).

Analogous to some previous observations (Ring and Bakke, 1955; Ball et al., 1956), the complete occlusion of the pulmonary stem in the present case did not imply any sign of pulmonary infarction.

A peculiar feature in our case was the large number of extremely dilated myocardial capillaries in the right ventricle, and to a lesser extent in the left ventricle. This close-meshed capillary network should possibly be considered to be a compensatory phenomenon (acute or chronic?) secondary to the heavy burden put on the myocardium.

Influenced by the study of the present case, we were interested to ascertain the incidence of congenital heart defects associated with primary thrombosis of the major pulmonary arteries. We have reviewed 394 consecutive necropsy cases with many kinds of cardiac anomalies presenting during the 20-year period $1946-65$ at the University Institute of Pathology, Rikshospitalet, Oslo. The series included 38 cases with tetralogy of Fallot ranging from 2 months to 36 years of age. There was only one example of primary pulmonary arterial thrombosis which occurred in a case of Fallot's tetralogy. This patient was a 28-year-old man; one month before death he rapidly developed signs of serious renal insufficiency terminating with anuria. Necropsy revealed a narrow pulmonary trunk almost completely occluded by an adherent thrombus. Microscopically, the kidneys showed the picture of a subacute glomerulonephritis without any signs of the glomerular alterations described in cases of cyanotic heart disease (Spear, 1960; Spear and Vitsky, 1966). It is doubtful whether the pulmonary thrombus was of any importance in relation to the fatal outcome in this case.

Our study indicates that cardiac anomalies are only rarely associated with primary thrombotic occlusion of the major pulmonary arteries.

\section{References}

Amos, J. A. S. (1958). Thrombosis of the major pulmonary arteries. British Medical fournal, 2, 659.

Ball, K., Goodwin, J. F., and Harrison, C. V. (1956). Massive thrombotic occlusion of the large pulmonary arteries. Circulation, 14, 766.

Best, P. V., and Heath, D. (1958). Pulmonary thrombosis in cyanotic congenital heart disease without pulmonary hypertension. Fournal of Pathology and Bacteriology, 75, 281.

Breining, H. (1965). Zur Kenntnis der Pulmonalarterienthrombose. Zeitschrift für Kreislaufforschung, 54, 254.

Brunck, H.-J. (1959). Primäre phlegmonöse Thrombarteriitis der A. pulmonalis bei einem Kleinkind. Zentralblatt für allgemeine Pathologie und pathologische Anatomie, 99, 56.

Dickinson, L. (1897). Thrombosis of the pulmonary artery in a case of congenital stenosis of the orifice. Transactions of the Pathological Society of London, 48, 57.

Dimond, E., and Jones, T. (1954). Pulmonary artery thrombosis simulating pulmonic valve stenosis with patent foramen ovale. American Heart fournal, 47, 105.

Ferencz, C. (1960). The pulmonary vascular bed in tetralogy of Fallot. Bulletin of the fohns Hopkins Hospital, 106, 81 and 100.

Ferencz, C. (1964). Pulmonary vascular changes in tetralogy of Fallot. Diseases of the Chest, 46, 664 .

Gehrt, D. (1923). Thrombose der Arteria pulmonalis im Kindesalter. Zeitschrift für Kinderheilkunde, 36, 221.

Gootman, N., Gross, J., and Mensch, A. (1964). Pulmonary artery thrombosis. Pediatrics, 34, 861 .

Gordon, H., and Perla, D. (1931). Subacute bacterial endarteritis of pulmonary artery associated with patent ductus arteriosus and pulmonic stenosis. American fournal of Diseases of Children, 41, 98.

Gunter, J. U. (1941). Thrombosis of the pulmonary artery in identical twins. Archives of Pathology, 31, 211.

Habib, R., Courtecuisse, V., and Bodaghi, E. (1968). Thrombose des artères pulmonaires dans les syndromes néphrotiques de l'enfant. Fournal d'Urologie et de Néphrologie, 74, 349.

Harvey, E. B., and Hogg, P. (1946). Thrombosis of the pulmonary artery in children. American fournal of Diseases of Children, 71, 67.

Hudson, R. E. B. (1965). Cardiovascular Pathology, pp. 1833-36. Edward Arnold, London.

Ihenacho, H. N. C., Breeze, G. R., Fletcher, D. J., and Stuart, J. (1973). Consumption coagulopathy in congenital heart-disease. Lancet, 1, 231.

Levin, S. E., Zamit, R., and Schmaman, A. (1967). Thrombosis of the pulmonary arteries and the nephrotic syndrome. British Medical fournal, 1, 153.

Rauchfuss, C. (1859). Ein Fall von Verstopfung der Lungenarterien eines 4 Wochen alten Kindes. Virchows Archiv für pathologische Anatomie, 17, 474.

Rich, A. R. (1948). A hitherto unrecognised tendency to the development of widespread pulmonary vascular obstruction in patients with congenital pulmonary stenosis (tetralogy of Fallot). Bulletin of the fohns Hopkins Hospital, 82, 389.

Ring, A., and Bakke, J. R. (1955). Chronic massive pulmonary artery thrombosis. Annals of Internal Medicine, 43, 781.

Robin, A. (1875). Physiologie pathologique d'un cas de gangrène du poumon, avec oblitération de l'artère pulmonaire chez un enfant atteint de rougeole et de bronchopneumonie consécutive. Progrès Médical, 3, 747.

Rosenkranz, A., and Weissenbacher, G. (1967). Thrombose der Lungenarterien als Komplikation des nephrotischen Syndroms. Wiener klinische Wochenschrift, 79, 320.

Rudolph, A. M., Nadas, A. S. and Borges, W. H. (1953). 
Hematologic adjustments to cyanotic congenital heart disease. Pediatrics, 11, 454.

Spear, G. S. (1960). Glomerular alterations in cyanotic congenital heart disease. Bulletin of the fohns Hopkins Hospital, 106, 347

Spear, G. S., and Vitsky, B. H. (1966). Hyalinization of afferent and efferent glomerular arterioles in cyanotic congenital heart disease. American fournal of Medicine, 41, 309.

Symchych, P., and Perrin, E. V. (1965). Thrombosis of the main pulmonary artery in nephrosis. American fournal of Diseases of Children, 110, 636.

Thomas, M. A. (1964). Pulmonary vascular changes in pulmonary stenosis with and without ventricular septal defect. British Heart fournal, 26, 655.
Tosetti, R., Actis Dato, A., and Angelino, P. F. (1953). Histo-pathologie des petits vaisseaux pulmonaires dans les sténoses congénitales de l'artère pulmonaire. Archives des Maladies du Coeur et des Vaisseaux, 46, 780.

Whipham, T. (1911). A heart showing an infective polypoid thrombus in the pulmonary artery and extending into the right ventricle, mistaken for patent ductus arteriosus. Proceedings of the Royal Society of Medicine, 4 (part 1), 199.

Requests for reprints to Dr. Sivert Svane, Department of Surgery, Central Hospital for Ostfold, 1600 Fredrikstad, Norway. 